\title{
INSECT RESPONSE TO THE 1988 FiRES IN Yellowstone National Park
}

\author{
ROBERT J. LAVIGNE — JEFFREY A. LOCKWOOD \\ Tim Christiansen $\downarrow$ SCOTT R. ShaW \\ Department of Plant, SoIl and InSECt ScIENCES — UnIVERSITY of Wyoming \\ LARAMIE
}

Collection of insect abundance and distribution data for the 1990 field season in Yellowstone National Park was initiated in early June, using several methods: litter sampling, pit traps, sweeping and Malaise traps. Final collections were made during the first week of September.

We are presently coding and entering data for analysis. Data analysis will be conducted in upcoming months (analysis of variance, regression, and multivariate analysis). Summary calculations of litter data are presented in Tables 1-3 compared with data obtained in 1989. Based on these initial comparisons, forest arthropod diversity changed only slightly, while densities increased at most sites.

\section{$\downarrow$ Literature Search}

A literature search was conducted using CARL during October, 1989 for papers dealing with insect research in Yellowstone National Park. An additional search was conducted in Entomology Abstracts. The results were disappointing, as only 12 papers were located. Subsequent searches of the taxonomic literature revealed a plethora of records of individual species. These published records have been compiled into a listing of species of insects known to occur in
Yellowstone National Park, a draft copy of which has been supplied to the Park.

\section{$\downarrow \quad$ IDENTIFICATIONS}

Slow progress is being made on obtaining identifications of various insect taxa. Thus far, identifications have been obtained on a portion of the material in the following groups: Acari, Annelida, Araneae, Chilopoda, Collembola, Diplopidea, Opiliones, Orthoptera, Lepidoptera, Hymenoptera, Neuroptera, and one family of Diptera. A summary of accomplishments for identification of Hymenoptera follows. 
Table 1. Comparisons of lodgepole pine (Pinus contorta) litter arthropod diversity, richness, and evennes between locations and the years 1989 and 1990.

Ecological Parameters
Diversity ${ }^{a}$
Density ${ }^{b}$
Richness $\mathrm{c}$
Evenness $^{\mathrm{d}}$

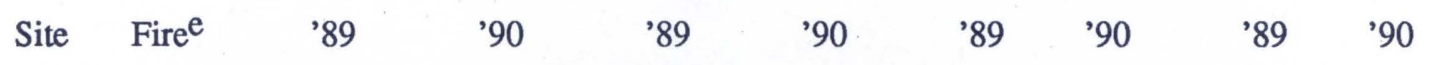

$\begin{array}{rrrrrrrrrr}1 & \mathrm{~N} & 2.78 & 2.72 & 139 & 2005 & 34 & 55 & .79 & .68 \\ & \mathrm{Y} & 1.33 & 1.73 & 209 & 509 & 19 & 24 & .45 & .55 \\ & & & & & & & & & \\ 2 & \mathrm{~N} & 3.28 & 2.67 & 334 & 1187 & 52 & 53 & .83 & .67 \\ & \mathrm{Y} & 2.43 & 2.51 & 116 & 240 & 24 & 27 & .77 & .76\end{array}$

$\begin{array}{rrrrrrrrrr}3 & \mathrm{~N} & 2.43 & 3.49 & 421 & 1104 & 46 & 80 & .64 & .80 \\ & \mathrm{Y} & 1.98 & 2.39 & 59 & 96 & 9 & 16 & .90 & .86\end{array}$

$\begin{array}{llllllllll}4 & \mathrm{~N} & 3.05 & 3.39 & 341 & 905 & 48 & 61 & .79 & .83 \\ & \mathrm{Y} & 2.24 & 1.49 & 146 & 515 & 22 & 25 & .73 & .46\end{array}$

$\begin{array}{rlllrlllll}5 & \mathrm{~N} & 3.01 & 3.26 & 268 & 279 & 39 & 47 & .82 & .85 \\ & \mathrm{Y} & 2.08 & 2.17 & 41 & 755 & 13 & 37 & .81 & .60\end{array}$

$\begin{array}{rrrrrrrrrr}6 & \mathrm{~N} & 2.97 & 2.82 & 837 & 723 & 53 & 43 & .75 & .75 \\ & \mathrm{Y} & 1.47 & 2.24 & 59 & 118 & 10 & 20 & .64 & .75\end{array}$

$\begin{array}{rrrrrrrrrr}7 & \mathrm{~N} & 3.22 & 2.71 & 397 & 1001 & 52 & 43 & .81 & .72 \\ & \mathrm{Y} & 2.49 & 3.00 & 46 & 144 & 16 & 29 & .90 & .89 \\ & & & & & & & & & \\ 8 & \mathrm{~N} & 3.41 & 3.01 & 417 & 1008 & 54 & 56 & .86 & .75 \\ & \mathrm{Y} & 2.18 & 2.39 & 109 & 66 & 21 & 15 & .72 & .88 \\ & & & & & & & & & \\ 9 & \mathrm{~N} & 3.18 & 2.57 & 242 & 1278 & 39 & 43 & .87 & .68 \\ & \mathrm{Y} & 2.34 & 2.64 & 56 & 102 & 16 & 21 & .85 & .87\end{array}$

aDiversity was calculated as the average Shannon-Weiner Index for natural logs in $45.5 \mathrm{~m}^{2}$ plots, in each site, from June to mid-September.

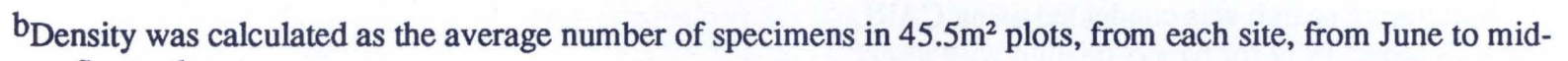
September.

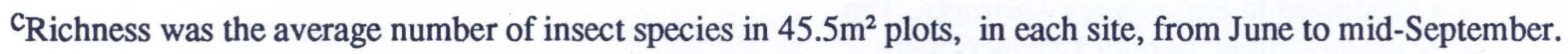

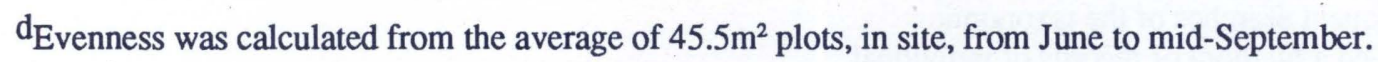

$\mathrm{e}_{\mathrm{N}}=$ Unburned sites.

$\mathrm{Y}=$ Intensively burned sites. 
Table 2. Comparisons of lodgeple pine litter insect diversity, density, richness, and evenness between locations and the years 1989 and 1990.

\section{Ecological Parameters}

Diversity ${ }^{a} \quad$ Density $^{b} \quad$ Richness $^{c} \quad$ Evenness $^{d}$

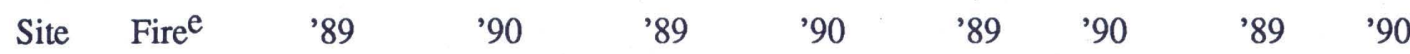

\begin{tabular}{|c|c|c|c|c|c|c|c|c|c|}
\hline 1 & $\mathrm{~N}$ & 2.52 & 2.21 & 44 & 180 & 17 & 15 & .89 & .82 \\
\hline & $Y$ & 1.72 & .31 & 28 & 254 & 8 & 6 & .83 & .17 \\
\hline 2 & $\mathrm{~N}$ & 2.60 & 1.25 & 135 & 553 & 22 & 18 & .84 & .43 \\
\hline & $\mathrm{Y}$ & 2.21 & 1.51 & 22 & 98 & 10 & 11 & .96 & .63 \\
\hline 3 & $\mathbf{N}$ & 2.30 & 2.46 & 76 & 107 & 15 & 22 & .85 & .80 \\
\hline & $\mathrm{Y}$ & .69 & 1.49 & 4 & 39 & 2 & 7 & 1.00 & .77 \\
\hline 4 & $\mathrm{~N}$ & 2.11 & 2.61 & 121 & 201 & 22 & 26 & .68 & .80 \\
\hline & $\mathrm{Y}$ & 1.95 & 2.30 & 24 & 20 & 10 & 10 & .85 & 1.00 \\
\hline 5 & $\mathrm{~N}$ & 2.21 & 2.40 & 48 & 79 & 13 & 21 & .86 & .79 \\
\hline & $\mathrm{Y}$ & 1.56 & 1.79 & 6 & 87 & 5 & 13 & .97 & .7 \\
\hline 6 & $\mathrm{~N}$ & 2.39 & 1.76 & 658 & 479 & 22 & 14 & .77 & .67 \\
\hline & $\mathrm{Y}$ & 1.06 & 1.89 & 5 & 18 & 3 & 7 & .96 & .97 \\
\hline 7 & $\mathrm{~N}$ & 2.54 & 1.21 & 59 & 209 & 18 & 13 & .88 & .4 \\
\hline & $\mathrm{Y}$ & .96 & 2.17 & 7 & 43 & 3 & 11 & .87 & .9 \\
\hline 8 & $\mathrm{~N}$ & 2.59 & 1.80 & 167 & 280 & 25 & 18 & .81 & .62 \\
\hline & $\mathrm{Y}$ & 1.00 & 1.39 & 68 & 8 & 8 & 4 & .48 & 1.00 \\
\hline & $\mathrm{N}$ & 2.23 & 1.21 & 84 & 695 & 15 & 12 & .82 & .49 \\
\hline & $\mathrm{Y}$ & 1.72 & 1.78 & 11 & 32 & 6 & 9 & .96 & \\
\hline
\end{tabular}

aDiversity was calculated as the average Shannon-Weiner Index for natural logs in $45.5 \mathrm{~m}^{2}$ plots, in each site, from June to mid-September.

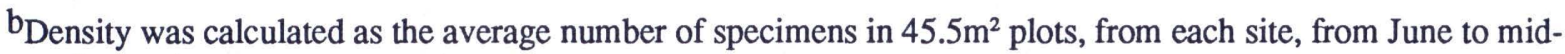
September.

${ }^{c}$ Richness was the average number of insect species in $45.5 \mathrm{~m}^{2}$ plots, in each site, from June to mid-September.

dEvenness was calculated from the average of $45.5 \mathrm{~m}^{2}$ plots, in site, from June to mid-September.

$\mathrm{e}_{\mathrm{N}}=$ Unburned sites.

$\mathrm{Y}=$ Intensively burned sites. 
Table 3. Comparisons of lodgepole pine litter noninsect diversity, density, richness, and evenness between locations and the years 1989 and 1990.

\begin{tabular}{|c|c|c|c|c|c|c|c|c|c|}
\hline \multirow[b]{3}{*}{ Site } & \multirow[b]{3}{*}{ Fire ${ }^{\mathrm{e}}$} & \multicolumn{6}{|c|}{ Ecological Parameters } & & \\
\hline & & \multicolumn{2}{|c|}{ Diversity ${ }^{a}$} & \multicolumn{2}{|c|}{ Densityb } & \multicolumn{2}{|c|}{ Richness $^{c}$} & \multicolumn{2}{|c|}{ Evenness $^{\mathrm{d}}$} \\
\hline & & '89 & '90 & '89 & '90 & '89 & '90 & '89 & '90 \\
\hline \multirow[t]{2}{*}{1} & $\mathrm{~N}$ & 1.99 & 2,44 & 95 & 1827 & 17 & 40 & .70 & .66 \\
\hline & Y & .81 & 1.74 & 181 & 253 & 11 & 18 & .34 & .60 \\
\hline \multirow[t]{2}{*}{2} & $\mathrm{~N}$ & 2.61 & 2.62 & 199 & 634 & 30 & 35 & .77 & .74 \\
\hline & Y & 1.89 & 2.06 & 94 & 142 & 14 & 16 & .72 & .74 \\
\hline \multirow[t]{2}{*}{3} & $\mathrm{~N}$ & 1.88 & 3.18 & 345 & 938 & 31 & 59 & .55 & .78 \\
\hline & $\mathrm{Y}$ & 1.81 & 1.87 & 55 & 57 & 7 & 9 & .93 & .85 \\
\hline \multirow[t]{2}{*}{4} & $\mathrm{~N}$ & $2.5^{r}$ & 2.93 & 220 & 704 & 26 & 35 & .78 & .83 \\
\hline & Y & .7 & 1.25 & 122 & 490 & 12 & 15 & .71 & .46 \\
\hline \multirow[t]{2}{*}{5} & $\mathrm{~N}$ & 51 & 2.76 & 220 & 200 & 26 & 26 & .80 & .85 \\
\hline & Y & $1 . \cdots$ & 1.80 & 35 & 666 & 8 & 24 & .81 & .57 \\
\hline \multirow[t]{2}{*}{6} & $\mathrm{~N}$ & 2.69 & 3.00 & 179 & 244 & 31 & 29 & .78 & .89 \\
\hline & $\mathrm{Y}$ & 1.19 & 1.74 & 54 & 90 & 7 & 13 & .61 & .68 \\
\hline \multirow[t]{2}{*}{7} & $\mathrm{~N}$ & 2.84 & 2.46 & 338 & 792 & 34 & 30 & .81 & .72 \\
\hline & Y & 2.29 & 2.49 & 40 & 101 & 13 & 18 & .89 & .86 \\
\hline \multirow[t]{2}{*}{8} & $\mathrm{~N}$ & 2.84 & 2.66 & 250 & 728 & 29 & 38 & .84 & .73 \\
\hline & Y & 2.32 & 2.11 & 41 & 58 & 13 & 11 & .93 & .88 \\
\hline \multirow[t]{2}{*}{9} & $\mathrm{~N}$ & 2.69 & 2.69 & 158 & 581 & 24 & 31 & .85 & .78 \\
\hline & $\mathrm{Y}$ & 1.88 & 2.12 & 45 & 70 & 10 & 12 & .82 & .85 \\
\hline \multicolumn{10}{|c|}{$\begin{array}{l}\text { a Diversity was calculated as the average Shannon-Weiner Index for natural logs in } 45.5 \mathrm{~m}^{2} \text { plots, in each site, fron } \\
\text { June to mid-September. }\end{array}$} \\
\hline \multicolumn{10}{|c|}{ 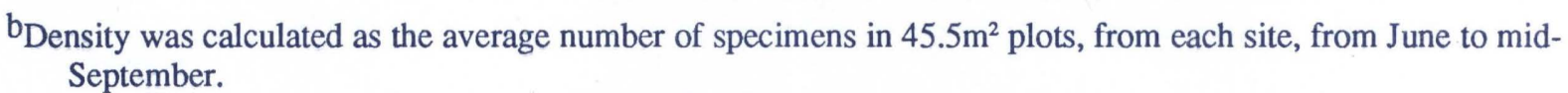 } \\
\hline \multirow{2}{*}{\multicolumn{10}{|c|}{ 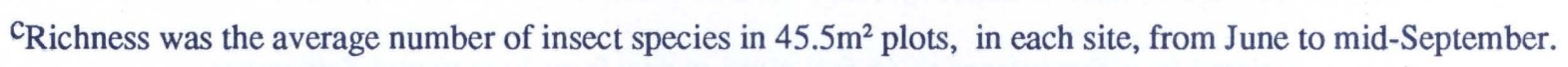 }} \\
\hline \multirow{2}{*}{\multicolumn{10}{|c|}{ dEvenness was calculated from the average of $45.5 \mathrm{~m}^{2}$ plots, in site, from June to mid-September. }} \\
\hline & & & & & & & & & \\
\hline \multicolumn{10}{|c|}{$\mathrm{e}_{\mathrm{N}}=$ Unburned sites. } \\
\hline
\end{tabular}




\section{Progress on 1990 Hymenoptera SAMPLeS}

During 1990 the sampling of Yellowstonee's Hymenoptera (wasp) species was greatly improved through the addition of four Malaise (passive flight intercept) traps to the study. During the season a total of 27 Malaise trap samples (1 pint Mason jars of flying insects trapped into alcohol) were collected. To date, all Hymenoptera have been sorted from Malaise trap samples into separate alcohol vials, and we are currently dry-mounting, labelling, sorting, and identifying these specimens. Mounting and labelling is being done by two student technicians working under the direction of Dr. Shaw. Approximately 1,024 specimens have been dry-mounted and labeled for study, representing perhaps $10-20 \%$ of the 1990 Hymenoptera samples. Remaining to be mounted are 11 four dram vials and 12 two dram vials of Hymenoptera samples; progress on these will now be more rapid with the addition of two student helpers. Only one burn-site sample has been fully sorted, with the following results [site 1ba, September 7, 1990]: 200 specimens total comprising $\mathbf{5 5}$ species, of which parasitoid species are clearly dominant, representing $53 / 55$ species. Remarkably, only two aculeate (stinging) species were present in this sample (one bee and one predatory wasp) and no phytophagous wasp species were present. Of the parasitoids, the dominant groups are Ichneumonoidea (28 species) and Chalcidoidea (13 species). The vast majority are parasitoids of larval stages of phytophagous insect larvae (especially Lepidoptera and Diptera species); however, also present were at least three species of insect egg parasitoids. Only one hyperparasitoid (Mesochorus) was present. The most abundant parasitoid species (both with 21 specimens) were a campoplegine ichneumonid (parasitoid of tortricoid moth larvae) and a platygastrid wasp (parasitoid of cecidomylid fly larvae). Only one parasitoid of woodboring beetle larvae was present. The majority of parasitoid species present are apparently utilizing leaffeeding hosts in the newly regenerating meadow habitat. During 1989 about 800 total hymenopterans were collected, of which $90 \%$ were aculeates (bees and predatory wasps).

These results may indicate that large, strong flying, flower-foraging hymenopterans were the first to migrate into burned areas, and to some extent insect host populations may not have been sufficiently developed to support parasitoids. However, this aberration may also be largely due to differences in the sampling methods. Sweep sampling, although done periodically, favors collection from low vegetation (especially flowers), and consequently tends to selectively sample greater numbers of aculeates (bees and predatory wasps). Malaise traps, on the other hand, sample flight activity around the clock, and consequently do a better job of sampling minute forms, widely dispersed individuals, and crepuscular of nocturnally active species. Whatever the reason, it is clear that Malaise traps do a far better job of sampling parasitoid Hymenoptera than sweep sampling alone, and given that most new migration into burned areas is by flying insects, Malaise traps are probably the best overall method for monitoring insect migration into these areas.

Our view is that future research should further emphasize the wasps, not only because they comprise one of the most diverse insect orders present, but also because they represent the highest trophic levels of insect diversity within the ecosystem (parasitoid wasps represent a tri-trophic level of diversity: parasitoid/host insect/host plant, thus are uniquely suited to serve as key- indicator organisms for population changes in the habitat). Our plans are to

1. continue preparation and study of Hymenoptera specimens and develop species inventories for the various habitats;

2. continue Malaise sampling of burned vs. unburned sites to gain comparative measures of both relative diversity and abundance of species;

3. evaluate abundant wasp species as possible key-indicator organisms (marking the presence of insect hosts and plant species that were not directly sampled); and

4. characterize the major parasitoid guilds present at different stages of succession.

\section{Databases}

We have created a database in Dbase IV, ver, 1.0, format, which ties together field collected data and identified material for 1989 and 1990. Date of collection by various methods is presented in Table 1 . As more arthropod taxa are identified, this data is being entered into the database. The intent is to be able to tie individual species to specific locations in Yellowstone National Park and to eventually map the distribution of individual species within the Park. We are presently coding and entering data on the VAX 
computer system for data analysis. We have accumulated nearly 3,500 blocks of data, of which $30 \%$ is now entered into VAX. In addition to the arthropod data, we are including stand data and abiotic data sampled from each site and for each sampling period over the last two years.

\section{$\checkmark \quad$ Data Analysis}

Stand structure data includes

1. litter biomass,

2. herbaceous cover,

3. seedling density,

4. log density,

5. sapling density,

6. standing dead tree density, and

7. density of mature trees.

Litter and herbaceous material was also sampled from each site for subsequent nutrient analysis. The nutrient data should be ready by the end of this year.

Biological data for litter includes
1. richness,

2. density,

3. evenness,

4. diversity and dominance of insect, spider, mite, centipede, millipede, and annelid populations in each site every ten days from June until mid-September. Data analysis will be conducted in terms of analysis of variance, regression, and multivariate analysis.

\section{$\downarrow \quad$ Results}

The second year's data has not yet been analyzed. Therefore no major comparisons have been made. However, summary calculations of litter data have been made (Tables 1-3) as comparisons with data obtained in 1989. Based on these comparisons, forest arthropod diversity changed only slightly, while densities increased at most sites. 